\title{
Correlation between Attitude and Practice Regarding Early Ambulation among Post-Operative Patients at Puducherry
}

\author{
Uma V ${ }^{1}$, Shruthikamal V.2 ${ }^{2}$ Jasmine J ${ }^{3}$ \\ ${ }^{1}$ Department of Nursing, Saveetha University, Thandalam, Chennai, India. ${ }^{2}$ Department of Surgery, \\ Saveetha Medical College and Hospital, Chennai, Tamilnadu, India. ${ }^{3}$ Department of Nursing, \\ Mother Teresa Post Graduate and Research Institute of Health Sciences, Puducherry, India.
}

\section{ABSTRACT}

\section{BACKGROUND}

The major responsibility for preparing the patient for surgery generally falls on the staff nurse. Nurse offers support, explains and verifies that the patient has understood the information provided by the other health team members and instructs the patient regarding what has to be done post-operatively. Pre-operative instructions like benefits of early ambulation may be given to the patient to reduce complications. Early ambulation will reduce unnecessary distress or suffering, it will improve patient's self-confidence and thereby facilitates early postoperative recovery. The aim of this study was to assess the attitude and practice regarding early ambulation among postoperative patients at selected hospitals, Puducherry.

\section{METHODS}

The study was conducted among 120 post-operative patients who had undergone surgery at selected hospitals, Puducherry. Patients were selected through convenient sampling technique. After obtaining consent, the researcher used close ended questionnaire to assess the attitude level with the help of a structured observational check list for practice regarding early ambulation.

\section{RESULTS}

Out of a total of 120 patients, majority (96, $80 \%$ ) had negative attitude, and 24 patients (20\%) had positive attitude. Most (105) of the patients (87\%) had inadequate practice with regard to early ambulation. A positive correlation exists between attitude with practice. Whenever the attitude level of the clients became negative, their practice level also decreases.

\section{CONCLUSIONS}

After surgery the patient may hesitate to walk due to pain, or lack of knowledge about the importance of ambulation etc. Creating awareness regarding the benefits of early ambulation will reduce length of hospital stay and improves the recovery process.

\author{
Corresponding Author: \\ Mrs. Uma V, \\ No :10, H-Cross, $12^{\text {th }}$ Main Road, \\ Krishna Nagar, Lawspet, \\ Puducherry, India. \\ E-mail: uma.jevika@gmail.com \\ DOI: $10.14260 / j e m d s / 2020 / 544$ \\ How to Cite This Article: \\ Uma V, Shruthikamal V, Jasmine J. \\ Correlation between attitude and practice \\ regarding early ambulation among post - \\ operative patients at Puducherry. I \\ Evolution Med Dent Sci 2020;9(35):2502- \\ 2506, DOI: $10.14260 /$ jemds/2020/544
}

Submission 27-05-2020,

Peer Review 23-07-2020,

Acceptance 28-07-2020,

Published 31-08-2020.

Copyright (C) 2020 JEMDS. This is an open access article distributed under Creative Commons Attribution License [Attribution 4.0 International (CC BY 4.0)]

\section{KEY WORDS}

Ambulation, Attitude, Practice 


\section{BACKGROUND}

Early ambulation is when a patient gets out of bed as soon as possible after surgery and engages in light activity (such as sitting, standing, walking). ${ }^{1}$ Further post-operatively, patients are monitored for fluid balance, drain and catheters care, and gut functions. All these are done to prevent the complications such as vomiting, pyrexia, wound failure etc. ${ }^{2}$

The art or work of treating diseases, injuries, or deformities by manual or operative procedures is known as surgery. It is the unique experience for the individual. Surgery may be carefully planned and anticipated event in a person's life coated at WHO guidelines for safe surgery, 2009. It is art done to treat illness. Surgical procedures involves interaction of the patients, a surgeon and the nurse. ${ }^{3}$

The major responsibility of the client for surgery generally falls on the staff nurse in the unit. Nurse offers support and explanation, verifies that client has understood information provided by the other health team members and instructs the client in specific to be done post operatively. Post-operative instructions may be given to the patient alone in a group or both. ${ }^{4}$

By giving post-operative teaching, patient don't experience unnecessary distress or suffering will improve patients self-confidence and thereby facilitates early postoperative recovery. ${ }^{5}$

Attitude is an individual's predisposed state of mind and it is precipitated through a responsive expression towards oneself. ${ }^{6}$ Early walking is most crucial things after surgery. Ambulation helps to reduce postoperative complications. It is a low-intensity activity does not require any special equipment. Post-surgical ambulation provides a large range of benefits for all patients. ${ }^{7}$

In addition, the prevalence and intensity of symptoms vary over the time but the most severe period is the first three days after surgery. It was pointed out that the percentage of patients reported at least moderate pain on the first day after abdominal surgery varied from $51 \%$ to $95 \%$. Nausea and vomiting also reach its peak in the first two days, with $66.5 \%$ of patients felt nauseated and $34 \%$ actually vomited. ${ }^{8}$

Furthermore, $92 \%$ of patients complained about the increase fatigue, $11 \%$ of patients reported difficulties in urination and $9.7 \%$ described dizziness after surgery. During first $48 \%$ hours post-operatively, the state anxiety score assessed by the state-trait anxiety inventory [STAI] was 29.4. In addition, score on the second day following abdominal surgery was 5.76 with hospital anxiety and depression scale and only mildly decreased in the next two days. The common problem arising after surgeries performed under general anesthesia are circulatory complications, problems of conscious, discomfort and respiratory tract complication. When the patient develops the post- operative complications it will result into increase in hospital stay as well as economic loss. ${ }^{9}$

A national survey in United States reported that operations on the digestive system is one of the three most frequently surgical procedures. Indeed, digestive system problems are one of many reasons for surgeon to enter abdominal cavity. ${ }^{10}$ The prevalence of intra-abdominal surgery among those in the age of 60 is $43.8 \%$. Notably, the rate of abdominal operation increases with age and females found to have a significant higher rate the male. ${ }^{11}$
At Tamilnadu, there are 100 patients diagnosed as acute appendicitis in tertiary care hospital during the year 2001 to 2002. One of hundred patients, $55 \%$ was male and $45 \%$ were female. Nearly $71 \%$ of the patients belonged to the age group of $15-30 \%$ years. $100 \%$ had pain abdomen, $81 \%$ had fever and $75 \%$ had vomiting. The Post-operative complication was $3 \%$. The complication of abdominal surgeries is very common and gives good prognosis. ${ }^{12,13}$

Recent advances in surgical techniques and peri-operative management have enabled expert surgeons to perform highly demanding and extended operation with acceptable mortality rates in specialized institutions. However, overall postoperative morbidity remains at $24-44 \%$ depending on the definitions used, the type of operation performed, and the patients complication considerable impair patients postoperative outcome, lengthening intensive care units and total hospital and increasing mortality. In view of the large numbers of operations caused out worldwide and the cost increases caused, postoperative complication burdens not only the individual patients but also the health care system. Thus the prevention of post-operative complication is of prime importance.

From the above studies and reports, it is found that knowledge, attitude and practice related to early ambulation is inadequate. It is important to get a patient up and move around as soon as able after surgery, because body systems slow down after anesthesia. Ambulating improves blood flow, increases the progress of wound healing, and improves physical, emotional function and social well-being. Hence, Ambulation is the most important factor in preventing postoperative complications. Nursing officers are the first person in the healthcare team to initiate early ambulation among post-operative patient. The mobilization of surgical patients is an often ignored aspect of post - operative care. So, creating positive attitude towards early ambulation among health workers and patients will increases the level of practice among post-operative patients.

\section{Objectives}

1. To assess the attitude and level of practice regarding early ambulation.

2. To correlate the attitude level with practice with regard to early ambulation.

\section{METHODS}

This is a cross sectional study conducted in selected hospitals, Puducherry. Variables studied were attitude and practice with regard to early ambulation. The study population included all post-operative patients in the age group of $20-80 \mathrm{yrs}$. who were posted for elective surgeries (abdominal, cardiac, urology and respiratory), willing to participate in the study and present during the period of data collection. They were selected by purposive sampling.

\section{Study Sample Size}

Sample size selected for this study was 120 . The sample size was calculated to obtain a power of $80 \%$ within a confidence interval of $95 \%$, suggested, 100 subjects. Thus, taken to an 
account of dropouts from the study a total of 120 patients were included in the study.

\section{Exclusion Criteria}

Patients who were

- unable to speak Tamil and English.

- critically ill.

- with systematic complications.

- unconscious and disoriented patients.

\section{Description of the Tool}

The instrument consists of 3 sections.

Section - A: This section consists of demographic variables such as patient's age, sex, education, occupation, marital status, history of previous surgery, duration etc.

Section - B: This section consists of closed ended Attitude questionnaire. It consists of 30 questions and validated by experts. Test - retest method was used to assess the reliability of the tool. The intra- class correlation coefficient for the tool was 0.978 , with $\mathrm{p}<0.001$.

Section - C: This section consists of observation check list to monitor the level of practice on ambulation. It consists of 27 statements and was assessed by two evaluators. Kappa statistics was applied. The kappa value was 0.9 which constitutes perfect agreements.

\section{RESULTS}

\begin{tabular}{|ccc|}
\hline Attitude Level & Frequency & Percentage \\
Positive Attitude & 24 & 20 \\
Negative Attitude & 96 & 80 \\
\hline \multicolumn{2}{|c|}{ Table 1. Distributions of Attitude Level } \\
\hline
\end{tabular}

The above table shows that most of subjects (96 patients) had negative attitude $(80 \%)$ and 24 patients $(20 \%)$ had positive attitude regarding early ambulation.

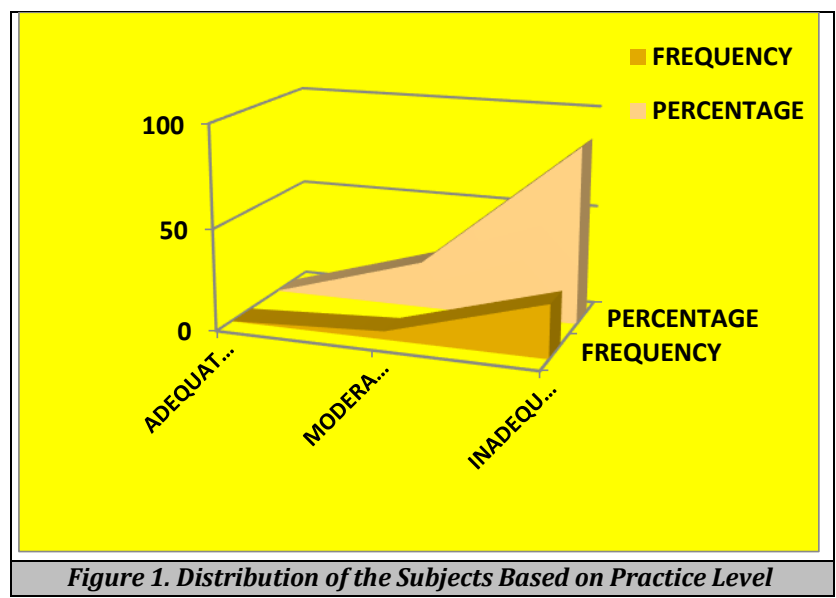

The above figure shows that majority of subjects had inadequate practice $87 \%$, least $23 \%$ had moderately adequate practice and none of them had adequate practice on early ambulation.

\begin{tabular}{|cc|}
\hline Correlation Coefficient & Practice \\
Attitude & $0.480^{* *}$ \\
$\mathrm{R}$ - value & $<0.001$ \\
$\mathrm{p}$ - value & ( $\mathbf{N}=\mathbf{1 2 0})$ \\
\hline Table 2. Correlation of the Level of Attitude with Practice \\
\hline $\mathrm{p}<0.05$ Significant, ${ }^{* *}$ Highly significant, NS - Nonsignificant $)$ \\
\hline
\end{tabular}

Table 2. Shows significant p-value infers that there was a significant relationship exists between the attitude levels with practice. The positive relationship exists between the attitude levels with practice, infers that whenever the attitude of the patient became negative $(r=0.480)$ their practice towards ambulation has been reduced.

\section{Regarding Attitude Level}

Most of subjects had negative attitude $80 \%$ and 6 patients $(20$ $\%$ ) had positive attitude regarding early ambulation.

\section{Regarding the Subjects Based on Practice Level}

Majority of subjects had inadequate practice $87 \%$, least $23 \%$ had moderately adequate practice and none of them had adequate practice on early ambulation.

\section{Regarding Correlation between Attitude with Practice}

It shows significant $p$-value $(<0.001)$ infers that there was a significant relationship exists between the attitude levels with practice. The positive relationship $(r=0.480)$ exists between the attitude levels with practice, infers that whenever the attitude of the patient became negative their practice towards ambulation has been reduced.

\section{DISCUSSION}

Majority of postoperative patients falls under the age group of above 55 age of years [70\%], most of them were female patients [60\%], [67\%] underwent secondary education. [60 \%] of them earn between Rs. 5000 to 10,000 and lead moderate lifestyle.

\section{Objective 1 - To Assess the Level of Attitude Regarding} Early Ambulation

The study result showed that, out of 120 patients, the majority 96 patients $(80 \%)$ had negative attitude, 24 patients $(20 \%)$ had positive attitude. The study result concluded that educational interventional was needed to increase the attitude level.

The study finding sustained with, Paula Caitano Fontela, Luiz Alberto Forgiarini Jr, Gilberto Friedman, ${ }^{14}$ Conducted A cross-sectional study regarding assessment of Clinical attitudes and perceived barriers to early mobilization of critically ill patients in adult intensive care units among 514 professionals such as, physicians, nursing professionals and physical therapists. The Results revealed, the accepted benefits of early ambulation, maintained the muscle strength (53\%) and shortened length of mechanical ventilation (83\%). The patients show Favourable attitudes and were aware of the benefits of early mobilization. The study Concludes, lack of 
professionals, time and excessive sedation are the perceived challenges for early mobilization.

\section{Objectives 2 - To Assess the Level of Practice Regarding Early Ambulation}

The study result showed most the 107 patients (87\%) had inadequate practice level regarding ambulation. The study finding Supported with Deepa, ${ }^{15}$ evaluated the effectiveness of early ambulation on postoperative recovery among 60 abdominal surgery patients. The results revealed, a low level of dependency in performing activity of daily living and level of discomfort following early ambulation ( $p<0.001 \mathrm{~s}$ ). The study concluded, postoperative recovery will be increased through early ambulation among surgical patients.

\section{Objectives 3 - To Correlate the Attitude Level with Practice Regarding Early Ambulation}

The study result revealed, a positive correlation exists between attitude with practice, infers that whenever the attitude level of the clients decreases their practice level also decreases. Hence it is enlightened the majority of the patient had negative attitude level about early ambulation.

The study result supported with TeKolste, Danielle; Currier, Danielle; Wheatley, Mary Anne, ${ }^{16}$ conducted evidence-based practice project in search of the Cochrane, PubMed, and Cinahl plus about effectiveness of early ambulation, improve patient outcomes. It revealed, early ambulation had a positive impact on physical, psychological, and social outcomes and decreased complications.

The study constituted with Kim CG, Moon, ${ }^{17}$ carried out a study to examine the effects of nursing information and patient's satisfaction about surgery among 54 patients at $\mathrm{K}$ University Hospital, Seoul. The patient's satisfaction level was assessed on 4th post- operative day by modified postoperative Satisfaction Scale. The result suggested, patients who received, planned nursing information shows higher satisfaction level than others $(\mathrm{t}=8.48, \mathrm{p}=0.0004)$. It concludes the patients satisfaction level will be increased through preoperative teaching about postoperative care.

The study comprised with Trent W. Stethen, Yasir A. Ghazi, Robert Eric Heidel, Brian J. Daley, Linda Barnes ${ }^{18}$ conducted on ambulation among 127 patients who had undergone bowel resection surgery. The result revealed, the median length of stay increased from 3.6 to 6.6 days $(\mathrm{p}<0.001)$ for the patients who were ambulated after 24 hours. It shows significant association between completed ambulation attempts and median Length of stay $(r=-0.536, p<0.001)$. It Concluded, adequate ambulation decreased Length of hospital stay.

\section{Limitations}

- $\quad$ A study period of 9 month.

- The study setting was selected hospitals, Puducherry.

- A sample size of 120 subjects.

\section{CONCLUSIONS}

Ambulation is a vital element of postoperative care. The ambulated patient shows key benefits which includes, less nausea, vomiting, reduced abdominal distention and postoperative pain. But, this intervention is not routinely practiced in hospitals. Now a days, many surgeries are performed on outpatient or day care basis. Patients defy early ambulation in the immediate postoperative period due to pain, nausea, etc. So, the targeted patients and their family members should be educated regarding the importance or significance of early ambulation pre-operatively. The health care personal have essential role to create positive attitude among patient and family members on the magnitude of early ambulation. We should encourage patients to get out of bed and move so that they can recover and get discharged earlier.

The study results show that, out of 120 patients, the majority 96 patients $(80 \%)$ had negative attitude. Regarding practice most the 107 patients ( $87 \%$ ) had inadequate practice level regarding ambulation. A positive correlation exists between attitude and practice. Therefore, creating awareness regarding the benefits of early ambulation will reduce the length of hospital stay. Ambulation can be a mandatory practice in postoperative unit in-order to improve the recovery process.

I hereby acknowledge to Dr. Sruthikamal and Dr. Jasmine for their support during the study.

Financial or Other Competing Interests: None.

\section{REFERENCES}

[1] Bean $\mathrm{H}$. What a patient thinks about early ambulation. Am J Nurs 1954;54(2):169-71.

[2] Kayilioglu SI, Dinc T, Sozen I, et al. Postoperative fluid management. World J Crit Care Med 2015;4(3):192-201.

[3] Kim FJ, da Silva RD, Gustafson D, et al. Current issues in patient safety in surgery: a review. Patient Saf Surg 2015;9:26.

[4] Ojuka DK, Okutoyi L, Otieno FC. Communication in surgery for patient safety. IntechOpen 2018. DOI: 10.5772/intechopen.79740.

[5] Fecho K, Lunney AT, Boysen PG, et al. Postoperative mortality after inpatient surgery: incidence and risk factors. Ther Clin Risk Manag 2008;4(4):681-8.

[6] Altmann TK. Attitude: a concept analysis. Nurs forum 2008;43(3):144-50.

[7] OakBend Medicals Center 2019. https://www.oakbendmedcenter.org/why-isambulation-important-to-recovery/

[8] Rüsch D, Eberhart LHJ, Wallenborn J, et al. Nausea and vomiting after surgery under general anesthesia: an evidence-based review concerning risk assessment, prevention, and treatment. Dtsch Arztebl Int 2010;107(42):733-41.

[9] Terry R, Niven K, Brodie E, et al. An exploration of the relationship between anxiety, expectations and memory 
for postoperative pain. Acute Pain 2007;9(3):135-43.

[10] Chung F, Un V, Su J. Postoperative symptoms 24 hours after ambulatory anaesthesia. Can J Anaesth 1996;43(11):1121-7.

[11] Nunoo-Mensah JW, Rosen M, Chan LS, et al. Prevalence of intra-abdominal surgery: what is an individual's lifetime risk? South Med J 2009;102(1):25-9.

[12] Babu KS, Savitha S. A study on acute appendicitis in a tertiary care hospital in Tamil Nadu, India. Int Surg J 2017;4(3):929-31.

[13] Halpern LW. Early ambulation is crucial for improving patient health. Am J Nurs 2017;117(6):15.

[14] Fontela PC, Forgiarini LA, Friedman G. Clinical attitudes and perceived barriers to early mobilization of critically ill patients in adult intensive care units. Rev Bras Ter Intensiva 2018:30(2):187-94.
[15] Deepa M. A study to assess the effectiveness of early ambulation on postoperative recovery of patients who have undergone abdominal surgery at railway hospital, Perambur, Chennai. WJPMR 2018;4(11):196-8.

[16] TeKolste D, Currier D, Wheatley MA. Why day zero matters in early ambulation for postoperative patients: an evidence-based project. Early Ambulation 2018.

[17] Kim CG, Moon MS. Effects of the provision of nursing information on patient's satisfaction after abdominal surgery. J Korean Acad Adult Nurs 1999;11(3):570-80.

[18] Stethen TW, Ghazi YA, Heidel RE, et al. Walking to recovery: the effects of missed ambulation events on postsurgical recovery after bowel resection. J Gastrointest Oncol 2018;9(5):953-61. 